\title{
OUTCOME OF HOSPITAL OUTPATIENT TREATMENT OF FUNCTIONAL GASTROINTESTINAL DISORDERS
}

Dr Chamara Basnayake*\# MBBS FRACP

Gastroenterologist

Prof Michael A Kamm*\#, MD PhD

Professor of Gastroenterology

Associate Prof Michael Salzberg\#

Associate Professor of Psychiatry

Miss Annalise Stanley*

Research nurse

Mrs Angela Khera*\#

Behavioural therapist

Mrs Kathryn Burrell*

Research nurse

Miss Amy Wilson-O’Brien*\#

Clinical scientist

Prof Geoffrey Hebbard\$\#

Professor of Gastroenterology

Prof Alexander J Thompson*\#

Professor of Gastroenterology

Corresponding author:

Professor Michael A Kamm

St Vincent's Hospital

Victoria parade

FITZROY 3065

Melbourne

This is the author manuscript accepted for publication and has undergone full peer review but has not been through the copyediting, typesetting, pagination and proofreading process, which may lead to differences between this version and the Version of Record. Please cite this article as doi: 10.1111/imj.14067

This article is protected by copyright. All rights reserved. 
Australia

Tel: +61 394175064

Fax: +6139416 2485

Email: mkamm@unimelb.edu.au

Affiliations: * Department of Gastroenterology, St Vincent's Hospital, Melbourne (CB,MAK, AJT, AK, KB, AWOB, AS). \#University of Melbourne, Melbourne, Australia (CB, MAK, MS, AK, AWOB, AJT). \$Royal Melbourne Hospital, Melbourne Australia Conflicts of interest:

No author has any conflict of interest.

\section{Author contributions:}

$\mathrm{CB}, \mathrm{MAK}, \mathrm{MS}$ and $\mathrm{AJT}$ devised the concept. $\mathrm{CB}$ and $\mathrm{AS}$ acquired the data under the supervision of MAK, MS, and AJT. GH contributed to the design of the protocol. CB, $A K, A W O B, K B$ and $A S$ developed the protocol in form submitted for ethical review. $\mathrm{CB}$ wrote the manuscript. MAK, MS and AJT provided critical revision of the manuscript for important intellectual content.

This article is protected by copyright. All rights reserved. 


\section{ABSTRACT}

Background: Functional gastrointestinal disorders (FGIDs), are the commonest conditions observed in gastrointestinal (GI) practice, yet the outcomes of their outpatient care are not known. We evaluated the outcome for patients with FGIDs attending a specialist GI clinic.

Methods: Consecutive, newly referred patients with a FGID attending a specialist GI clinic in a tertiary hospital, over a one-year period were reviewed and then completed a phone survey to assess current symptoms.

Results: Of 102 patients 57\% had IBS, 28\% functional dyspepsia (FD) and 15\% other functional disorders. At interview a median of 402 days after the last consultation $38 \%$ expressed symptom improvement, but $64 \%$ remained concerned about their condition despite $62 \%$ having been reassured. After treatment $50 \%$ of employed patients took time off work because of gut symptoms. FD patients were less likely to be symptomatically improved than other FGIDs ( $21 \%$ vs $45 \%, \mathrm{P}=0.02)$. Patients given a low-FODMAP diet were more likely than others to achieve symptom improvement (53\% vs 31\%, P=0.03); PPI-treated patients were less likely to experience improvement ( $22 \%$ vs $44 \%, \mathrm{P}=0.05)$; other treatments did not predict outcome. Number of visits, seniority of clinician, duration of care, and co-morbidities did not predict outcome.

This article is protected by copyright. All rights reserved. 
Conclusions One year after attending a specialist GI clinic a minority of patients with FGIDs were symptomatically improved. Failure to benefit by many patients may relate to the nature of patients and conditions being treated or the limited nature and range of treatments offered. Different models of care, including more diverse multi-disciplinary models, should be explored.

Keywords: Irritable bowel syndrome, Functional gastrointestinal disorders, Hospital outpatient clinics

\section{INTRODUCTION}

Functional gastrointestinal disorders (FGIDs) are the commonest reason patients consult with a gastroenterologist and are among the most common presentations to general practitioners.[1] These conditions, characterised by the absence of detectable physical pathology[2], include Irritable bowel syndrome (IBS), functional dyspepsia (FD) and constipation[3]. Despite the high prevalence[4] and health service burden[5] of these disorders, there are almost no published data about the clinical outcomes of FGID patients who attend gastroenterology specialist clinics.

The economic burden of FGIDs on the healthcare system is considerable. The conservative estimate for costs associated with IBS alone in the US is US\$1 billion per year [6]. This estimate does not incorporate the significant secondary costs associated with FGIDs, which include impaired workforce productivity[7]. The cost of public hospital gastroenterological outpatient care in Australia is estimated to be

This article is protected by copyright. All rights reserved. 
greater than $\$ 126$ million per year[8]; given their high prevalence it is likely that a significant portion of this relates to FGIDs. FGIDs are also an important public health problem, given that they are highly prevalent, impair well-being for otherwise healthy individuals, and are economically costly.[2] Studies of the efficacy of outpatient care for FGIDs are warranted.

Numerous clinical trials have demonstrated the efficacy of a range of therapies for FGIDs. Patients with constipation benefit from behaviourally-based therapies, including "biofeedback" [9, 10]. Gut-focussed hypnotherapy provides a sustained mitigation of symptoms of abdominal pain and bloating[11]. The severity of abdominal pain and diarrhoea can be alleviated by reducing fermentable oligosaccharides, disaccharides and polyols (FODMAPs) in the diet[12]. A variety of drugs can be used to treat symptoms[13, 14]. Despite the availability of these therapies it is unclear to what extent they are utilised by gastroenterologists.

Therapies outside the use of medication appear to be underutilised, with most centres employing a traditional, 'doctor-only' service model. Several therapies for FGIDs are best provided by ancillary therapists, notably dieticians, psychologists, and physiotherapists. While a few highly specialised functional gut centres incorporate these therapists into the clinical team[10,11], most secondary and tertiary hospital clinics operate on a 'traditional' doctor-only model, involving only gastroenterologists.

To our knowledge the outcome of secondary outpatient care for the treatment of irritable bowel syndrome, without a defined therapy, has been described in only one cohort [15]. Only quality of life after attending a gastroenterology clinic was examined, with no change observed.

This article is protected by copyright. All rights reserved. 
The aim of this study was to assess the outcome of care of FGIDs in traditional doctor-only clinics. We aimed to determine (i) the clinical care that had been provided and (ii) symptom outcomes and (iii) and predictors of symptomatic outcome

This article is protected by copyright. All rights reserved. 


\section{METHODS}

\section{Centre characteristics}

At this secondary and tertiary hospital, located in Melbourne, Australia, patients who require specialist care can be referred by general practitioners and specialists. The gastroenterology clinic is staffed by consultant gastroenterologists, gastroenterology registrars and junior medical staff. No ancillary therapists work within this clinic. The clinic manages patients with a full range of gastroenterological conditions.

\section{Recruitment}

All consecutive new patient referrals seen in the Gastroenterology clinic at this one hospital over a 12-month period between October 2015 and October 2016 were assessed. Functional gastrointestinal disorders were defined by the criteria set in Rome IV[3] and patients with an apparent FGID then included. Patients were excluded who were non-English speaking, prisoners, incapable of answering questions, refused telephone interview, or did not have healthcare coverage.

\section{Patient characteristics collected}

A review of the hospital record was conducted recording patient demographics, time spent on the clinic waiting list, number of visits to the clinic and seniority of the treating clinician. Clinical factors recorded from the patient record included: symptoms, comorbidities (including psychological disorders, past abdominal surgery), medications at presentation, investigations conducted and treatments offered. Symptoms were used to classify the patient according to Rome IV criteria.[3]

\section{Assessment of current symptoms - telephone interview}

All included patients were contacted by telephone to conduct a short, structured interview (Table 1) approximately one year after discharge from the outpatient

This article is protected by copyright. All rights reserved. 
clinic. The interview addressed patients' expectations of the clinic, experience during clinical care, and state of symptoms after attending the clinic. Patients were excluded if they were unable to be contacted after three calls on three separate days or refused to participate.

Patients were asked to quantify their current symptoms, in comparison to before their clinic attendance, as 1) much worse, 2) worse, 3) same, 4) better or 5) resolved.

Patients who self-defined their symptoms as better or resolved were defined as a positive outcome.

This article is protected by copyright. All rights reserved. 


\section{RESULTS}

\section{Patients Characteristics}

Of 580 new patients seen in the clinic over a 12-month period, 231 had a functional gastrointestinal disorder. Of these 152 qualified for inclusion. One hundred and two patients were evaluated, completed the survey, and form the basis of this study's results (figure 1 ).

*Insert figure 1 here*

Patients' median age was 43 years, and 65 percent were female. Eighty eight percent of patients were referred by a general practitioner (table 2 ).

*Insert Table 2 here*

\section{Clinic characteristics}

Patients waited a median of 195 days before being seen in the clinic. During their care, patients had a median of 2 visits in the clinic over a median 115 days. 35 patients were discharged after their $1^{\text {st }}$ visit to the clinic.

\section{*Insert table 3 here*}

\section{Seniority of clinician caring for the patient}

Ninety-two patients (90\%) were seen in the clinic by a consultant gastroenterologist at least once, 27 (26\%) were seen by a gastroenterology specialist registrar at least once, $6(6 \%)$ were seen by a resident or medical student at least once.

This article is protected by copyright. All rights reserved. 
Functional symptoms and conditions

The most common symptoms documented were abdominal pain $(n=71)$ and diarrhoea $(n=57)$ (table 2). The most common functional disorders observed in this cohort were irritable bowel syndrome and functional dyspepsia (table 3).

\section{Medications at presentation to clinic}

At referral nine patients were on opiate therapy, 44 were taking either a protonpump inhibitor or histamine-2 receptor antagonist, 6 were taking laxatives, and 19 were taking an anti-depressant or anxiolytic.

\section{Management}

Investigations and treatments Arranged in the Clinic

Seventy-four (73\%) patients had an endoscopy (11 colonoscopy, 22 gastroduodenoscopy, and 41 gastroduodenoscopy and colonoscopy).

Thirty (29\%) patients were not offered any treatment. Thirty-four (33\%) were offered a low-FODMAP diet, 27 (26\%) a proton-pump inhibitor, and 11 (11\%) laxatives (table 3).

\section{Evaluation of Clinical Outcomes}

Survey Results

The median time from the last visit to the hospital to the time of survey was 403 days (IQR 264 to 501).

*insert table 4 \& 5 here*

Symptoms at follow-up

This article is protected by copyright. All rights reserved. 
Thirty-eight percent of patients felt their symptoms were better or resolved at the time of the follow-up. Sixty one percent of patients felt their symptoms were the same or worse. (figure 2)

Sixty five (64\%) patients remain concerned about their symptoms at the time of follow-up. In the 12 months prior to follow-up 30 of the 60 working patients had had some work absence due to their Gl symptoms, of whom seven patients were absent from work for at one week or longer.

\section{Further medical consultation and investigations after clinic discharge}

Seventeen (17\%) patients consulted other doctors for their functional gut symptoms after discharge from the clinic. Of these 13 had further blood tests, 6 imaging (MRI, ultrasound or $\mathrm{CT}$ ) and 3 endoscopy.

\section{Predictors of symptom improvement}

Patients with functional dyspepsia were less likely to have symptom improvement at the time of survey than patients with other symptoms at presentation ( $21 \%$ vs $45 \%$, $p=0.02$ ). Patients with reflux-like symptoms were less likely to have symptom improvement than those without ( $27 \%$ vs $46 \%, p=0.04)$. Other symptoms or functional gut diagnoses did not predict symptom improvement. Age, gender, source of referral, time spent on waiting list, arranging endoscopy and number of visits in the clinic were not associated with symptom improvement, nor were a past history of surgery or psychiatric comorbidity. Medications at baseline were not associated with symptom improvement.

A dietician-led low FODMAP diet, for patients with any functional gut diagnosis, was associated with symptom improvement at the time of follow-up (low FODMAP diet

This article is protected by copyright. All rights reserved. 
prescribed $53 \%$ vs no diet $31 \%, p=0.03$ ). Patients with a diagnosis of IBS were also more likely to feel improved if provided with a dietician-led low FODMAP diet compared to those not provided with dietary instruction, although this difference did not reach statistical significance ( $52 \%$ vs $34 \%, p=0.103$ ).

Sixty three percent of patients with functional upper gastrointestinal symptoms were prescribed a proton pump inhibitor. Patients prescribed a proton-pump inhibitor were less likely to report symptom improvement (PPI prescribed $22 \%$ vs no PPI 44\%, $p=0.05)$.

Patients who had no documented treatment provided did not differ significantly in relation to final follow-up outcome from patients who were provided one or more treatments. No other treatment was associated with an increased rate of symptom improvement.

Of the patients who recalled symptom improvement shortly after discharge, $76 \%$ reported this was still the case at the time of survey $(p=0.0001)$. Patients who recalled being provided reassurance were more likely to have symptom improvement ( $46 \%$ vs $26 \%, p=0.031$ ). Patients who remain concerned about their symptoms were less likely to have symptom improvement ( $26 \%$ vs $57 \%, p=0.001$ ).

This article is protected by copyright. All rights reserved. 


\section{DISCUSSION}

Despite the high prevalence of functional gut disorders and the vast resources spent on their management, there are almost no data on the outcomes of such care. This evaluation of the outcome of care for patients with a functional gut disorder seen in a specialist gastroenterology hospital clinic has identified that the majority of patients were not improved on follow-up. A majority of patients remained symptomatic and concerned about their symptoms.

To our knowledge, this is the first assessment of the outcome of outpatient specialist hospital care for patients with functional gut symptoms.

To appreciate better why patients' symptoms persisted and why they were often not satisfied with their care, careful consideration needs to be given to the variables in the therapeutic situation: the nature of the treating doctors, the therapeutic paradigm, the patients and their symptoms.

Although this study was conducted in a single centre, we believe this specialist clinic is reflective of public hospital specialist GI care in a developed country. The consultants were all experienced in treating these disorders, and most patients had input from a senior consultant at least once. All were familiar with treatment guidelines for functional gut disorders. However, we have not conducted an analysis of their skills in managing functional disorders. The nature of the care provided by gastroenterologists for these disorders remains a critical issue.

In our clinic the management of functional disorders is along the lines of accepted, published, therapeutic pathways $[16,17]$.This study suggests that such management strategies, when applied in clinical practice, often do not achieve satisfactory

This article is protected by copyright. All rights reserved. 
outcomes. These strategies are often based around drug therapy, but also sometimes include dietary manipulation, and rarely the involvement of disciplines related to gastroenterology and medicine such as psychologists, behavioural therapists, and psychiatrists.

The use of proton pump inhibitors for functional dyspepsia was often associated with a negative outcome. Despite their recommended use in guidelines [18], it is likely that patients who are symptomatic enough to seek specialist opinion have a basis to their symptoms that is not solely reflux related. The failure to respond to a proton pump inhibitor prior to specialist referral should prompt a more comprehensive approach.

Anti-depressants were offered to only three patients, despite their established efficacy in modulating symptoms for irritable bowel syndrome[19], functional pain[20] and functional dyspepsia [21].

In our cohort some patients receiving dietary advice did appear to benefit. Dietetic advice was available concurrent with the gastroenterology clinic. However allied therapists (psychologists, behavioural therapists) were not part of the gastroenterology clinic, access to them was limited, and they were rarely included in management. This is despite the strong evidence that such therapists are valuable in managing these disorders[10, 20, 22]. We believe the use of first-line, multidisciplinary therapies in an integrated clinical situation, for functional gut disorders, requires evaluation.

The vast majority of patients were referred by their general practitioner. They were not predominantly patients resistant to treatment who had seen multiple other doctors previously. However, there may be factors of importance in the patient 
population which influences the outcomes observed. This was a publically funded clinic, which is likely to have a different demographic than patients who seek private specialist care. Such differences may include social and work status, financial status, the desire to spend personal money on a health outcome, and mental health morbidity. Examination of these factors, and a comparison of outcomes to those in a private health care setting, are needed.

Lastly, is this symptom complex difficult to improve? Most drug studies for functional disorders have modest beneficial effects [23]. In most studies only a minority of patients benefit. Reported outcomes are usually short term. For many patients in drug studies, and in the clinical setting, drug therapy alone does not provide symptom relief and patient satisfaction[24] In contrast, behavioural and psychologically based studies have demonstrated more impressive outcomes with a majority of patients benefitting $[19-22,25,26]$, and with benefits sustained in the medium to long term $[10,11,27]$.

In terms of the nature of these patients and their symptoms, which are likely to influence the outcome of care, a further consideration is the way patients perceive their condition. Patients with functional gut disorders often have a negative view of life and catastrophize their situation and their symptoms. Patients' perceptions of the clinic experience are influenced by negative "illness attitudes" [28]. These patients also have a higher incidence of depression and anxiety than matched asymptomatic populations [29]. We believe attention to this cognitive aspect, and to mood disorders, needs to be a part of the consultation and management strategy.

This cohort highlights a disconnect between patient expectations, perception of the interaction with their clinician, and the therapeutic strategy employed by clinicians. The majority of patients expected detailed testing, provision of a diagnosis, and an 
offer of treatment. Seventy two percent of patients had a documented treatment offered in the clinic yet only 41 percent of patients recalled being offered a treatment.

In conclusion, this evaluation of the outcome of specialist hospital care for functional gut disorders has demonstrated that only a minority of patients perceive that they have benefitted. This study calls into question the usual outpatient specialist clinic approach to the management of functional gut disorders. To improve outcomes, each aspect of this approach needs to be evaluated, ranging from the nature of who is referred to what type of care is delivered, and who delivers it.

This article is protected by copyright. All rights reserved. 


\section{REFERENCES}

1. Mitchell, C.M. and D.A. Drossman, Survey of the AGA membership relating to patients with functional gastrointestinal disorders. Gastroenterology, 1987. 92(5 Pt 1): p. 1282-4.

2. Talley, N.J., Functional gastrointestinal disorders as a public health problem. Neurogastroenterol Motil, 2008. 20 Suppl 1: p. 121-129.

3. Drossman, D.A., Functional Gastrointestinal Disorders: History, Pathophysiology, Clinical Features and Rome IV. Gastroenterology, 2016. 150(6): p. 1262-1279e2.

4. Boyce, P.M., et al., Epidemiology of the functional gastrointestinal disorders diagnosed according to Rome II criteria: An Australian population-based study. Internal Medicine Journal, 2006. 36(1): p. 28-36.

5. Canavan, C., J. West, and T. Card, The epidemiology of irritable bowel syndrome. Clinical Epidemiology, 2014. 6: p. 71-80.

6. Ford, A.C., B.E. Lacy, and N.J. Talley, Irritable Bowel Syndrome. N Engl J Med, 2017. 376(26): p. 2566-2578.

7. Dean, B.B., et al., Impairment in work productivity and health-related quality of life in patients with IBS. Am J Manag Care, 2005. 11(1 Suppl): p. S17-26.

8. Australian hospital statistics. 2013, Australian Institute of Health and welfare. p. 104.

9. Chiarioni, G., L. Salandini, and W.E. Whitehead, Biofeedback Benefits Only Patients With Outlet Dysfunction, Not Patients With Isolated Slow Transit Constipation. Gastroenterology, 2005. 129(1): p. 86-97.

10. Chiotakakou-Faliakou, E., et al., Biofeedback provides long-term benefit for patients with intractable, slow and normal transit constipation. Gut, 1998. 42(4): p. 517-21.

This article is protected by copyright. All rights reserved. 
11. Miller, V., et al., Hypnotherapy for irritable bowel syndrome: an audit of one thousand adult patients. Aliment Pharmacol Ther, 2015. 41(9): p. 844-55.

12. Halmos, E.P., et al., A diet low in FODMAPs reduces symptoms of irritable bowel syndrome. Gastroenterology, 2014. 146(1): p. 67-75 e5.

13. Lembo, A.J., et al., Eluxadoline for Irritable Bowel Syndrome with Diarrhea. N Engl J Med, 2016. 374(3): p. 242-53.

14. Rao, S.S.C., et al., Effect of Linaclotide on Severe Abdominal Symptoms in Patients With Irritable Bowel Syndrome With Constipation. Clinical Gastroenterology and Hepatology, 2014. 12(4): p. 616-623.

15. Canavan, C., J. West, and T. Card, Change in Quality of Life for Patients with Irritable Bowel Syndrome following Referral to a Gastroenterologist: A Cohort Study. PLoS One, 2015. 10(10): p. e0139389.

16. Bharucha, A.E., J.H. Pemberton, and G.R. Locke, American gastroenterological association technical review on constipation. Gastroenterology, 2013. 144(1): p. 218-238.

17. Chang, L., A. Lembo, and S. Sultan, American gastroenterological association institute technical review on the pharmacological management of irritable bowel syndrome. Gastroenterology, 2014. 147(5): p. 1149-1172.e2.

18. Pinto-Sanchez, M.I., et al., Proton pump inhibitors for functional dyspepsia. Cochrane Database Syst Rev, 2017. 11: p. Cd011194.

19. Creed, F., et al., The cost-effectiveness of psychotherapy and paroxetine for severe irritable bowel syndrome. Gastroenterology, 2003. 124(2): p. 303-17.

20. Drossman, D.A., et al., Cognitive-behavioral therapy versus education and desipramine versus placebo for moderate to severe functional bowel disorders. Gastroenterology, 2003. 125(1): p. 19-31.

21. Talley, N.J., et al., Effect of Amitriptyline and Escitalopram on Functional Dyspepsia: A Multicenter, Randomized Controlled Study. Gastroenterology, 2015. 149(2): p. 340-9 e2. 
22. Whorwell, P.J., A. Prior, and E.B. Faragher, Controlled trial of hypnotherapy in the treatment of severe refractory irritable-bowel syndrome. Lancet, 1984. 2(8414): p. 1232-4.

23. Pimentel, M., et al., Antibiotic treatment of constipation-predominant irritable bowel syndrome. Digestive Diseases and Sciences, 2014. 59(6): p. 1278-1285.

24. Drossman, D.A., et al., International survey of patients with ibs: symptom features and their severity, health status, treatments, and risk taking to achieve clinical benefit. Journal of clinical gastroenterology, 2009. 43(6): p. 541-550.

25. Chiarioni, G., et al., Biofeedback is superior to laxatives for normal transit constipation due to pelvic floor dyssynergia. Gastroenterology, 2006. 130(3): p. 657-64.

26. Norton, C., et al., Randomized controlled trial of biofeedback for fecal incontinence. Gastroenterology, 2003. 125(5): p. 1320-9.

27. Yang, L.S., A. Khera, and M.A. Kamm, Outcome of behavioural treatment for idiopathic chronic constipation. Intern Med J, 2014. 44(9): p. 858-64.

28. Gomborone, J., et al., Abnormal illness attitudes in patients with irritable bowel syndrome. Journal of Psychosomatic Research, 1995. 39(2): p. 227-230.

29. Whitehead, W.E., O. Palsson, and K.R. Jones, Systematic review of the comorbidity of irritable bowel syndrome with other disorders: What are the causes and implications? Gastroenterology, 2002. 122(4): p. 1140-1156.

\section{Table 1: Phone call survey}

\section{Pre Clinic:}

What did you expect from attending the outpatient clinic? 


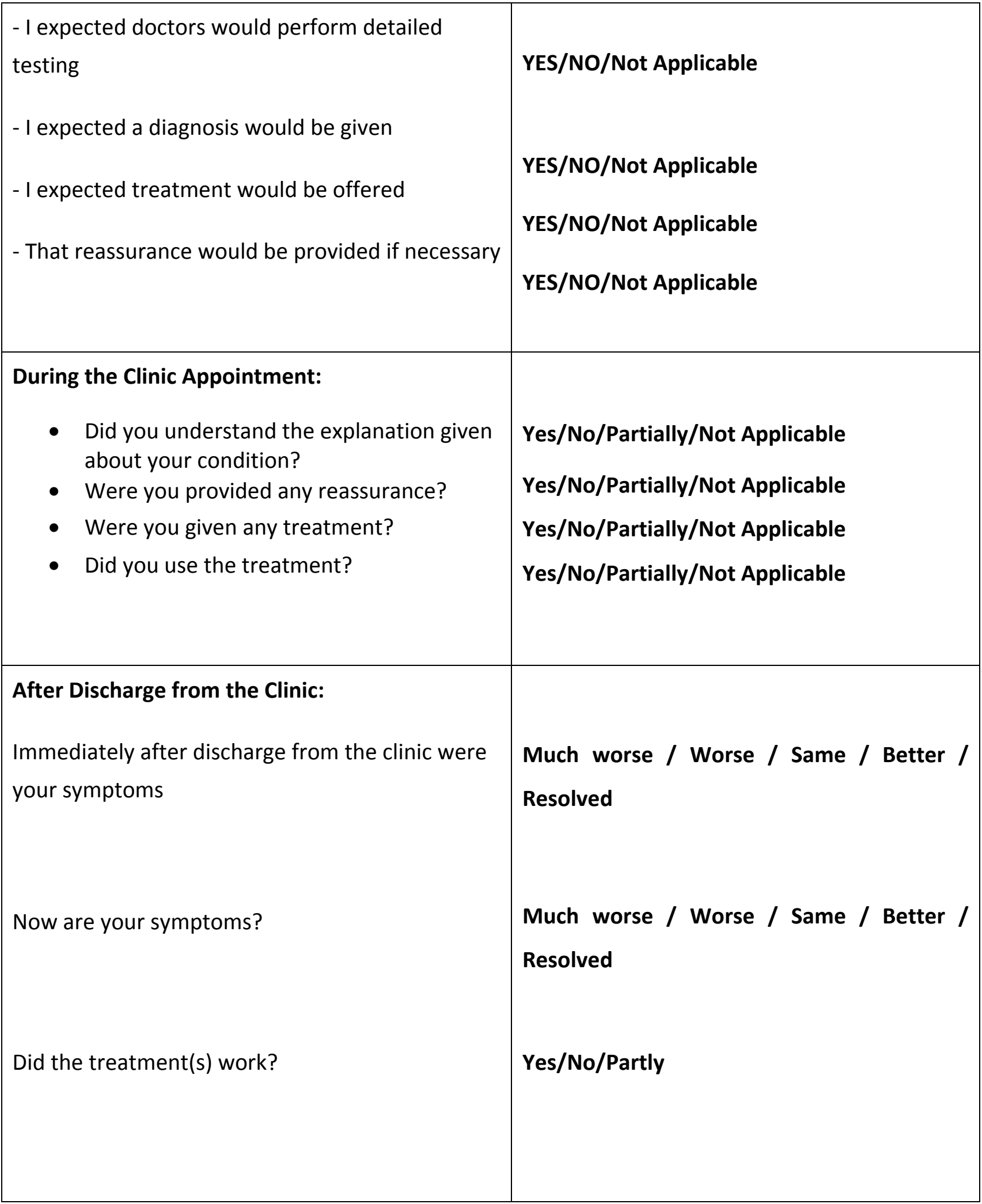

This article is protected by copyright. All rights reserved. 


\begin{tabular}{|l|l|}
\hline Are you still concerned about your symptoms? & Yes/No \\
\hline $\begin{array}{l}\text { Have you had any further tests or treatment for } \\
\text { your gut symptoms since your outpatient }\end{array}$ & Yes/No \\
treatment & Yes/No \\
- Endoscopy & Yes/No \\
- Blood tests & Yes/No \\
- Other & Yes/No \\
- Seeing other doctors & Yes/No \\
In the past 12 months how many days have you & Days \\
taken off work for your gut symptoms? &
\end{tabular}

Figure 1: Consort diagram - Patients included in cohort

This article is protected by copyright. All rights reserved. 


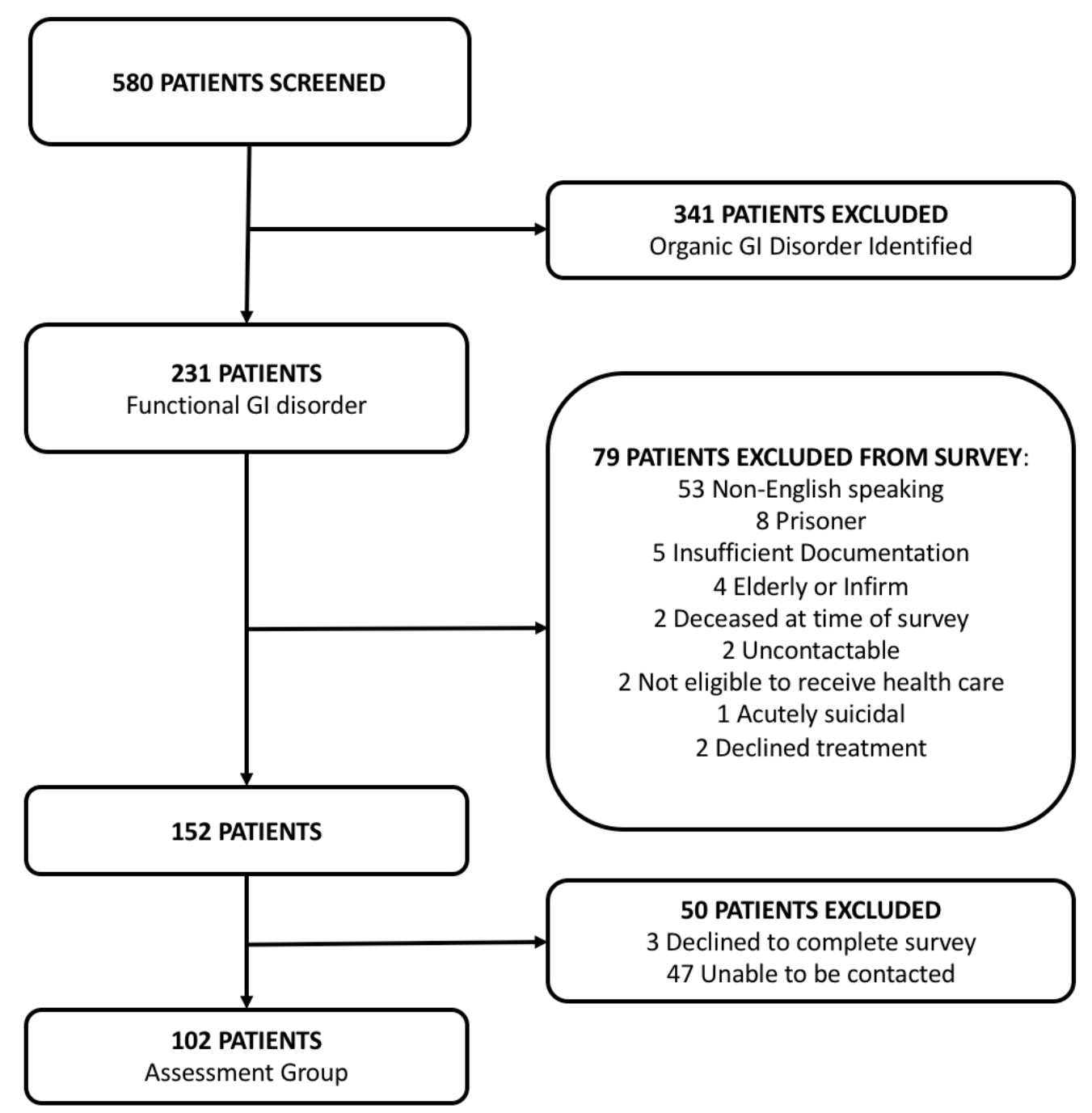

This article is protected by copyright. All rights reserved. 
Table 2 - Patient and referral characteristics:

\begin{tabular}{|l|l|}
\hline & $n=102$ \\
\hline Female & $66(65 \%)$ \\
\hline Who referred the patient? & $43(18-78)$ \\
\hline General practitioner & \\
Non-gastroenterologist specialist from treating hospital & $90(88 \%)$ \\
Non-gastroenterologist specialist from outside centre & $7(7 \%)$ \\
Emergency Department & $2(2 \%)$ \\
$3(3 \%)$
\end{tabular}

Table 3-Outpatient clinic characteristics

\begin{tabular}{|l|l|}
\hline Days from referral to $1^{\text {st }}$ visit (median) & 195 \\
\hline Days from $1^{\text {st }}$ visit to discharge (median) & 115 \\
\hline Number of clinic visits: & Median = 2 visits \\
1 & 35 \\
3 & 37 \\
4 & 19 \\
5 & 7 \\
\hline All gut symptoms at presentation & 2 \\
\hline Abdominal pain & Number of patients (\%) \\
\hline
\end{tabular}

This article is protected by copyright. All rights reserved. 


\begin{tabular}{|c|c|}
\hline Diarrhoea & $57(56 \%)$ \\
\hline Constipation & $44(43 \%)$ \\
\hline Dyspepsia & $42(41 \%)$ \\
\hline Reflux & $41(40 \%)$ \\
\hline Bloating & $39(38 \%)$ \\
\hline Nausea and vomiting & $29(28 \%)$ \\
\hline Belching and rumination & $12(12 \%)$ \\
\hline Incontinence & $3(3 \%)$ \\
\hline Functional diagnosis & Number of patients (\%) \\
\hline Irritable bowel syndrome & $58(57 \%)$ \\
\hline Functional dyspepsia & $29(28 \%)$ \\
\hline Constipation & $7(7 \%)$ \\
\hline Faecal incontinence & $2(2 \%)$ \\
\hline Non-cardiac chest pain & $2(2 \%)$ \\
\hline Other & $4(4 \%)$ \\
\hline Comorbidities & \\
\hline $\begin{array}{l}\text { Documented psychological } \\
\text { comorbidities }\end{array}$ & $33(33 \%)$ \\
\hline - Anxiety only & $9(9 \%)$ \\
\hline - Depression only & $11(11 \%)$ \\
\hline - Anxiety and depression & $10(10 \%)$ \\
\hline - Other psychiatric illness & \\
\hline
\end{tabular}

This article is protected by copyright. All rights reserved. 
Surgical History

- Gynaecological surgery

$13(13 \%)$

- GI Surgery

$8(8 \%)$

Table 4-Treatments offered

\begin{tabular}{|l|l|}
\hline TREATMENT & $\mathrm{n}=102$ \\
\hline No treatment & 30 \\
\hline Low-FODMAP diet & 34 \\
\hline Proton-pump inhibitor & 27 \\
\hline Laxatives & 11 \\
\hline Lifestyle advice & 9 \\
\hline Behavioural therapy (Biofeedback) & 4 \\
\hline $\begin{array}{l}\text { Domperidone } \\
\text { Anti-depressant }\end{array}$ & 3 \\
\hline $\begin{array}{l}\text { Rifaximin } \\
\text { Modify fibre intake }\end{array}$ & 2 \\
\hline $\begin{array}{l}\text { Other } \\
\text { Psychotherapy } \\
\text { Loperamide } \\
\text { Kiwifruit extract } \\
\text { Cholestyramine } \\
\text { Other dietary intervention } \\
\text { Meberine }\end{array}$ & 10 \\
\hline
\end{tabular}

This article is protected by copyright. All rights reserved. 
Table 5: Expectations of the clinic prior to attendance

\begin{tabular}{|l|l|l|l|}
\hline \multicolumn{4}{|l|}{ QUESTIONS TO EVALUATE THE PATIENT'S EXPECTATIONS PRIOR TO ATTENDING THE CLINIC } \\
\hline $\begin{array}{l}\text { I expected that doctors would perform } \\
\text { detailed testing: }\end{array}$ & $93(91 \%)$ & $8(8 \%)$ & $1(1 \%)$ \\
\hline I expected a diagnosis would be given & $81(79 \%)$ & $21(21 \%)$ & 0 \\
\hline I expected treatment would be offered & $82(80 \%)$ & $18(18 \%)$ & $2(2 \%)$ \\
\hline $\begin{array}{l}\text { That reassurance would be provided, } \\
\text { if necessary }\end{array}$ & $88(86 \%)$ & $10(10 \%)$ & $4(4 \%)$ \\
\hline
\end{tabular}

Table 6: Patients recollection of experience in the clinic

\begin{tabular}{|l|l|l|l|l|}
\hline \multicolumn{2}{|l|}{ QUESTIONS EVALUATING EXPERIENCE IN CLINIC } \\
\hline $\begin{array}{l}\text { Did you understand the } \\
\text { explanation given about your } \\
\text { condition? }\end{array}$ & $70(68 \%)$ & $19(19 \%)$ & $11(11 \%)$ & $2(2 \%)$ \\
\hline $\begin{array}{l}\text { Were you provided any } \\
\text { reassurance? }\end{array}$ & $49(48 \%)$ & $14(14 \%)$ & $34(33 \%)$ & $5(5 \%)$ \\
\hline Were you given any treatment? & $26(25 \%)$ & $16(16 \%)$ & $58(57 \%)$ & $2(2 \%)$ \\
\hline Did you use the treatment? & $28(27 \%)$ & $7(7 \%)$ & $9(9 \%)$ & $58(57 \%)$ \\
\hline
\end{tabular}

Figure 2 - Symptoms at follow-up

Compared with before you were seen what are your symptoms now?

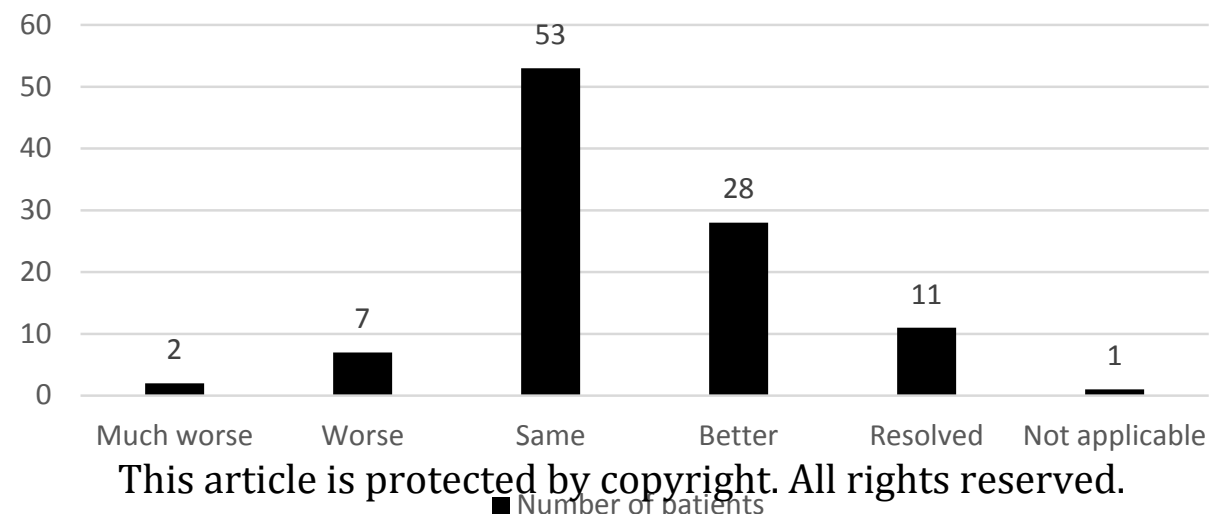




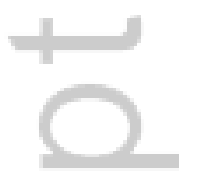

This article is protected by copyright. All rights reserved. 
580 PATIENTS SCREENED

\section{PATIENTS EXCLUDED}

Organic GI Disorder Identified

231 PATIENTS

Functional GI disorder

\section{PATIENTS}

79 PATIENTS EXCLUDED FROM SURVEY:

53 Non-English speaking

8 Prisoner

5 Insufficient Documentation

4 Elderly or Infirm

2 Deceased at time of survey

2 Uncontactable

2 Not eligible to receive health care

1 Acutely suicidal

2 Declined treatment

\section{PATIENTS EXCLUDED}

3 Declined to complete survey

47 Unable to be contacted

\section{PATIENTS}

Assessment Group

Figure 1.png 


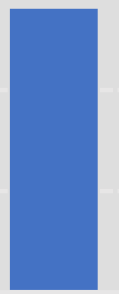

Much Worse Same Better Resolved Not Worse

Figure 2.png 


\section{University Library}

\section{- M M N E R VA A gateway to Melbourne's research publications}

Minerva Access is the Institutional Repository of The University of Melbourne

\section{Author/s:}

Basnayake, C;Kamm, MA;Salzberg, M;Stanley, A;Khera, A;Burrell, K;Wilson-O'Brien, A;Hebbard, G;Thompson, AJ

Title:

Outcome of hospital outpatient treatment of functional gastrointestinal disorders

Date:

2019-02-01

\section{Citation:}

Basnayake, C., Kamm, M. A., Salzberg, M., Stanley, A., Khera, A., Burrell, K., WilsonO'Brien, A., Hebbard, G. \& Thompson, A. J. (2019). Outcome of hospital outpatient treatment of functional gastrointestinal disorders. INTERNAL MEDICINE JOURNAL, 49 (2), pp.225-231. https://doi.org/10.1111/imj.14067.

Persistent Link:

http://hdl.handle.net/11343/285398 